\title{
Long term management of congenital cataracts
}

\author{
E C BURNS AND R B JONES
}

Moorfields Eye Hospital and Donald Winnicott Centre, Queen Elizabeth Hospital for Children, London

SUMMARY Presentation and outcome, particularly in terms of development, nursery, and school placement of 55 children with treated congenital cataracts was studied. Results indicate that although most children have satisfactory vision many of their parents would have welcomed more support at the time of the diagnosis, an opportunity to talk to parents of similarly affected children, and further advice on their child's early development and educational placement. It is suggested that improved communications between clinicians, therapists, and teachers, and parents' support groups would be helpful to these families.

Over the past 10 years there have been considerable improvements in the treatment of children with congenital cataracts. A greater understanding of amblyopia, the development of more sophisticated instruments for lens removal, and advances in the field of contact lens technology mean that bilateral congenital cataract is now the most common treatable cause of blindness in infancy. ${ }^{12}$

Surgery is usually performed soon after presentation, although occasionally it may be delayed when there is sufficient clear lens to allow an adequate image to be formed on the retina. Considerable evidence now exists to suggest that early surgery and optical correction lead to better visual results, and some effects of visual deprivation may be expected when the cataracts are left untreated beyond 4 months of age. In the infant, the aphakia is usually corrected by contact lenses. At 3 to 5 years, when an interest in near and far detail develops, a two lens system is required and bifocal spectacles are generally used. ${ }^{3} \mathrm{~A}$ few infants cannot tolerate lenses and in others parents find insertion and maintenance difficult. In these children spectacles may be used directly after lens removal.

During the preschool years the developmental progress and visual acuity of the corrected aphakic child requires repeated assessment so that appropriate educational plans may be made. Many of these children manage in a normal school, although their degree of visual impairment may necessitate the use of various visual aids or possibly transfer to a partially sighted unit when increasing demands are made upon their vision as they grow older. ${ }^{4}$

The management of the child with congenital cataracts involves many people including ophthalmologists, paediatricians, community physicians, peripatetic teachers of the visually impaired, educational psychologists, and teachers, and there are a number of areas where problems may arise. The parents, having coped with the trauma of an infant with a visual handicap and the early surgical treatment, become intimately involved in the care of their child's lenses and may have many years of uncertainty as to his ultimate vision and future educational needs. Undoubtedly the many difficulties which the families of these children experience are offset by the excellent visual results in most patients, but we wondered if there was any way to minimise the problems. We therefore asked the parents of a group of children with congenital cataracts to complete a questionnaire on their child's early management and subsequent progress.

\section{Subjects and methods}

Although the term congenital implies present at birth, we have included children in whom cataracts were evident within the first 12 months of life. The names of patients with this diagnosis were obtained from the medical records coding system at Moorfields Eye Hospital, and the notes of the 75 most recently referred patients over the age of 18 months on April 1984, were examined. Twenty patients did not meet our criteria.

The remaining 55 patients were initially referred to Moorfields for treatment of their cataracts or for advice concerning further management, and although 43 continue to be followed up there, 12 are now reviewed by a local ophthalmologist. Details of the patient's presentation, investigations, surgical management, and subsequent progress were obtained from the ophthalmic and paediatric notes. 
The questionnaire was sent to the parents of 53 of the 55 children (one family had emigrated and one child had recently died of an unrelated problem). In six the questionnaire was returned 'address unknown', in two it was returned unanswered, in 13 it was not returned, and in 32 it was returned completed. Details of the questionnaire are given in the Appendix.

\section{Results}

The 55 patients with congenital cataracts had a mean age of 5.1 years (range 1.6 to 20.3 ) at the time of the study. There were 33 boys and 22 girls.

Presentation and diagnosis. The children presented to an ophthalmologist at a mean age of 0.23 years (range 0.0 to $1 \cdot 0$ ). In most it was the mother who first noticed the cataracts; the exceptions were grandmother in two, midwife in one, father in two, and paediatrician in two. It was not always possible to determine the interval between recognition of the cataracts and referral to an ophthalmologist, but in some this was as long as two months. In all but three children, the infant was seen by an ophthalmologist within two weeks of referral and in none was this greater than four weeks.

Thirty eight patients were referred directly to Moorfields and 17 were seen first by another ophthalmologist. The cataracts were bilateral at presentation in all but two. A number of children had additional ophthalmic abnormalities: nystagmus (15), microphthalmus (8), squint (7), persistent hypoplastic primary vitreous (1), microcornea (1), macular dystrophy (1), and rubella fundus (1). There was a positive family history of cataracts in $\mathbf{3 0}$ (29 autosomal dominant, one autosomal recessive) and 12 children had a sibling in the study. Of those with a negative history two had Down's syndrome, two boys had Lowe's syndrome, one child had congenital rubella, one had Hallerman-Streiff syndrome, one had dysmorphic features and mental retardation of unknown aetiology, and the mother of one child had a low red cell galactokinase. ${ }^{5}$ The remaining 17 children were physically and developmentally normal: three were tested for congenital infection, 11 for metabolic disorder, and five had no investigations. The cases of sporadic congenital cataracts were thought to be new dominant mutations or possibly non-genetic; the parents were counselled that they had an approximate recurrence risk of 1 in 40 in further children.

Forty five children had bilateral cataracts removed surgically: 33 were then fitted with contact lenses and 12 given spectacles. Two underwent bilateral needling, another unilateral lens aspira- tions, three were treated medically with atropine, two had unilateral surgery and a lens implant, and two received no specific treatment. One child developed endopthalmitis after surgery which resulted in a right phthisical eye and a left retinal detachment. Five others had complications that adversly affected their vision-hypopyon and hyphema one, detached retina two, and uveitis two.

Outcome-early management. Seventy seven per cent of parents felt they had a reasonable understanding of their child's condition at diagnosis and before surgery. The others would have liked to know:

(1) How much the child would see later.

(2) What caused the cataracts.

(3) What were the chances of future children being similarly affected.

Thirty five children (64\%) were seen by a paediatrician at the time the cataracts were diagnosed. Of those who were not, five parents thought that this would have been helpful. Eighty per cent of parents said they would have welcomed talking to parents of children with cataracts who had been through a similar experience and $74 \%$ said they would have liked more support from their health visitor and general practitioner.

Outcome-development, nursery and school placement. Because of the varying ages and abilities of the children in this study visual acuity estimations for near and distance are not available in each case. Details of nursery and school placement, however, do give some idea of their visual and cognitive functions.

Eight are too young to attend nursery, but the most recent assessments suggest they all have adequate vision and abilities to manage in normal nursery. Five attended a nursery for the visually impaired and four of these are now going to schools for the visually handicapped. Thirty six are attending, or have attended, normal nursery; three of these have moved to a unit for the partially sighted attached to a normal school and 16 are going to normal school. Eight of those at normal school use a variety of visual aids (binoculars for board work, magnifying glass and extra light for reading, and sloping desk for holding books). There are six children who are educationally subnormal in addition to having a visual handicap, and they all attend special schools.

Forty per cent of parents had been anxious about the child's early development and would have appreciated guidance about appropriate stimulation. Many parents felt that they had received insufficient advice about nursery $(49 \%)$ and school 
(43\%) placement. Only six of the 16 parents who had discussed the child's vision with teachers felt that they had understood their child's problem.

The availability of peripatetic teachers of the visually impaired in the United Kingdom depends on the area. Fifty eight per cent of the children had never been visited by a peripatetic teacher. Thirteen had been seen and in 11 the parents found the sessions instructive and helpful-the two exceptions commented that the teacher was very 'blind orientated' and keen on schools for the visually impaired; which they felt was inappropriate for their child at that time.

Learning to insert and maintain contact lenses in infants and toddlers is a difficult process. No parents had any ideas on how the teaching of this might be improved, but a number stated that practice was essential and that ease of access to advice (from the contact lens department or the ward sister) about problems that might arise was most reassuring.

\section{Discussion}

Our data confirm that the outcome of current ophthalmic treatment in congenital cataracts is generally good in terms of the children's visual ability. The more general management as perceived by the parents, however, does not seem to have been entirely satisfactory.

A number of points relating to the patient's early care emerge. Firstly, that mothers' concern about a white spot in the pupil was often not taken as seriously as it should have been by those whom she initially consulted. As early diagnosis and treatment affect outcome ${ }^{6}$ it would seem prudent for any doctor or health visitor to arrange for an ophthalmic opinion in such a case, even when not convinced that there is an abnormality present. Although most parents felt that after speaking to the ophthalmologist they had a reasonable understanding of their child's condition and proposed treatment, particularly where other members of the family were affected, there were some who did not. They would have liked to have been able to talk to someone about the future and their fears about the condition, and have an explanation of how it might affect their child's development. They did, however, want to talk to someone with a reasonable knowledge of congenital cataracts and some recognised that their general practitioner and health visitor, although well meaning, were often unable to answer their queries. A paediatrician would seem the appropriate person with whom to discuss these anxieties and should be involved in the initial care of these children so that a full examination and appropriate investigations can be instituted. ${ }^{7}$ In this series only $64 \%$ of patients were seen by a paediatrician initially, although almost all are being followed up by one now.

The final point to be made about the early management is the very positive response to the question about meeting parents of other children with congenital cataracts. It seems that many parents felt lonely and isolated during their child's first years and many had not heard of cataracts in children before the condition was diagnosed. In the United States, a parents group for children with congenital cataracts has been operating successfully for some years ${ }^{8}$ and there seems to be a need for a similar network here. In addition to giving the parents an opportunity to share their feelings with people who have had a similar experience, these meetings would provide a channel through which solutions to later difficulties could be found.

A number of parents were anxious about their child's early developmental progress even though this subsequently turned out to be perfectly normal. It has been shown that visual input is important for those aspects of learning that are directly concerned with the concrete environment and also that vision is relevant to language development. ${ }^{9}$ Children with a visual disability thus benefit from specific early help. Some parents would have welcomed guidance and also an assurance that a 'normal', visually impaired child's development might apparently be delayed.

Planning and providing appropriate educational facilities for children with impaired vision is not an easy task and the relative rarity of the problems makes it difficult for skilled workers to be available everywhere. In the early years there are problems in predicting exactly which child will manage in a normal nursery and school; in borderline cases it is generally best for the child to attend a normal nursery, the staff there having been alerted to the visual difficulties. In this setting the child's progress can be closely monitored and a more prolonged assessment of his abilities made. The questionnaire replies indicate that advice about nursery and school placement was often unsatisfactory and many felt that getting their child to a normal school had involved 'a battle with the educational authorities'. When in school the problems continued and even after discussion with the headmaster and educational psychologist a number complained that their child's difficulties were not really understood by the teachers in the classroom.

Clearly our data illustrate the problems of coordinating the developmental and educational needs of children with congenital cataracts. The patients considered come from different areas in the south east of England and thus the findings do not reflect the management of any one education or health authority. Good communications are obviously 
essential and the key figures should be the ophthalmologist and the developmental paediatrician. The latter is in an excellent position to have further discussions with the parents about their child's future, can notify the general practitioner and district community physician about any potential difficulties, and inform the peripatetic teacher of the child's existence so that mother can be visited at home and advice given about handling the infant. Later when the child's visual abilities and developmental progress can be more accurately assessed, discussion and advice about nursery and school placement can be made by a team who have known the child and family for some time. If difficulties do arise in school the peripatetic teacher and paediatrician should offer advice and suggestions. It is hoped that as increasing numbers of these children are educated in normal schools their difficulties will become more readily appreciated and solutions rapidly found.

In summary, this study indicates that the current long term management of children with congenital cataracts has not matched recent advances in ophthalmic care, but that this could be improved considerably by better communication with parents.

\section{Appendix-questionnaire}

(1) When you first learnt from the ophthalmologist (eye doctor) that your child had cataracts and surgical treatment was proposed did you feel that you had a reasonable understanding of the situation?

And if not what further information would you have liked to know at this stage?

(2) If you did not see a paediatrician (children's doctor) around the time that the diagnosis of cataracts was made, do you think that this would have been helpful? and if so why?

(3) Is there anything that you know now that would have been useful to know when your child's cataracts were first diagnosed? (4) Do you think it would have been helpful to talk to the parents of other children with cataracts after your child's condition was diagnosed?

(5) Would you have welcomed extra support locally from your GP or health visitor around the time that the cataracts were discovered and diagnosed?

(6) If your child wore contact lenses after surgery, do you have any suggestions as to how teaching you to insert and remove the lenses might have been helpful?
The next set of questions concerns your child's general progress since the cataracts were diagnosed and removed.

(1) What sort of vision does your child have now with his lenses or glasses?

(2) Do you have or did you have any worries about your child's general development?

(3) Does or did he/she go to a normal nursery-and if so did you think this was helpful?

(4) If your child attends a normal school does he/she:

(a) Use any visual aids and if so which?

(b) Have you discussed his/her eye problem with the headmaster or educational psychologist? and if so do you think they fully understood the situation?

(5) Do you feel that you have had sufficient help and guidance concerning your child's:

(a) Development.

(b) Nursery placement.

(c) Schooling.

If not what extra help would you have liked and from where?

(6) Were you at any time visited by a peripatetic teacher for the visually impaired? If so was this helpful?

(7) Do you have any worries about your child's general health?

(8) Does your child see a paediatrician regularly?

We thank our ophthalmic colleagues at Moorfields Eye Hospital for allowing us to study their patients.

\section{References}

${ }^{1}$ Rice NSC, Taylor D. Congenital cataracts a cause of preventable blindness in children. $B r$ Med $J$ 1982;285:581-2.

2 Taylor D. Developments in the treatment of cataracts. Trans Ophthalmol Soc UK 1982;102:441-53.

3 Calhoun JH. Cataracts in children. Pediatr Clin North Am 1983;30:1061-9.

4 Chapman EK. Visually handicapped children and young people. London: Routledge and Kegan Paul Ltd, 1978:44.

5 Winder AF, Claringbold LJ, Jones RB, et al. Partial galactose disorders in families with premature cataracts. Arch Dis Child 1983;58:362-6.

6 Jacobson SG, Mohindra I, Held R. Development of visual acuity in infants with congenital cataracts. Br J Ophthalmol 1981;65:727-35.

7 Jay B. Cataracts in early childhood. Aetiology and genetics. Proceedings of the Royal Society of Medicine 1976;69:268-9.

${ }^{8}$ Moller MA. The visually handicapped child. Pediatr Clin North Am 1983;30:1185-93.

9 Reynell J. Developmental patterns of visually handicapped children. Child Care Health Dev 1978;4:291-303.

Correspondence to Dr R B Jones, Moorfields Eye Hospital, City Road, London EC1V 1PD.

Received 10 December 1984 